\title{
APONTAMENTOS SOBRE VARNHAGEN E CAPISTRANO DE ABREU $\left({ }^{\star}\right)$.
}

\author{
A. P. CANABRAVA \\ Da Faculdade de Ciências Econômicas e Administrativas \\ da Universidade de São Paulo.
}

A fundação do Instituto Histórico e Geográfico Brasileiro, em 1838, constitui um marco na historiografia brasileira, pela grande influência que exerceu como o mais importante centro de estudos históricos no país até a criação das Faculdades de Filosofia. Fundado durante a Regência, menos de duas décadas depois da independência do país, uma das feições que distinguiram seus trabalhos foi o nativismo, que também se revela em outros setores da vida intelectual do país. $\tilde{A}$ exaltação das benemerências do país, no plano material, acrescenta-se o louvor aos filhos, "varões preclaros" e "distintos pelo saber e brilhantes qualidades", os quais a História cumpria perpetuar como modêlo "nos caminhos da honra e da gloria nacional". Expressão do nativismo seria o interêsse pelo estudo do índio como tema para dissertação e debate, o enaltecimento quanto à sua influência na formação brasileira. As biografias constituem uma seç̧ão da Revista do Instituto, qual galeria de vidas exemplares que deveriam inspirar o comportamento dos jovens e estimular as repetições dessas experiências no futuro. $\mathrm{O}$ gênero biográfico tornou-se um dos mais cultivados pelos historiadores do Instituto.

A História formulada pelos historiadores dessa entidade assumiu alguns aspectos que vão caracterizá-la pelos anos restantes do século. O culto do documento é uma das diretrizes do método histórico. Através das páginas da Revista e da rêde de membros correspondentes em todo o território nacional, efetua-se intensa pesquisa de documen-

(*). - Comunicação apresentada à Mesa-Redonda, promovida pelo Núcleo Regional do Paraná da Associação Nacional dos Professôres Universitários de História (ANPUH), por ocasião da XXIII Reunião Anual da Sociedade Brasileira para o Progresso da Ciência (SBPC), em Curitiba, no dia 5 de julho de 1971 (Nota da Redação). 
tos, preceituada como um dos objetivos da fundação do Instituto, ampliados com as buscas arqueológicas, geográficas e etnográficas. Fundaram-se nas províncias entidades congêneres, inspiradas nos mesmos objetivos. Sob o patrocínio do Instituto, pesquisas especiais realizaram-se em várias partes do Império e em países da Europa, com o propósito de desvendar peças documentais relativas ao passado brasileiro. Os resultados foram magnifícos, pois revelou-se incalculável acervo de documentos, publicados em parte, que até hoje continua a inspirar trabalhos de interpretação e análise. A Revista tornou-se órgão divulgador de peças documentais, qualifícando-a como instrumento de investigação imprescindível para a História do Brasil. Todos os Institutos provinciais publicaram a sua Revista. Os escritos aí divulgados constituem testemunho precioso de como se concebia a reflexĩo histórica, ou seja, o trabalho do Historiador .

Francisco Adolfo de Varnhagen (1816-1878), vinculou-se ao Instituto, desde 1840, como sócio correspondente. Sua História Geral do Brsail (1854), afastou-se de algumas tendências que marcavam a mentalidade dos homens daquele sodalício, como o indianismo, mas ligou-se aos. seus grandes objetivos. E' o monumento da historiografia brasileira do século XIX.

A vocação de Varnhagen manifestou-se desde cêdo, "antiga e espontânea vocação", contaria êle, quando historiador já renomado. Seus dotes de pesquisador, foram sem dúvida estimulados pelas circunstâncias felizes de sua atividade profissional na carreira diplomática, desde 1842, que the possibilitaram longa premanência em países europeus, sobretudo Portugal e Espanha. Para sua fortuna foi o iniciador da tarefa, ainda não terminada, da pesquisa sistemática nos arquivos estrangeiros, o que the valeu o achado de numerosas peças documentais, sobretudo quanto ao século XVI. A sua "nova História", como o Autor a chamava com orgulho, abasteceu-se de valioso material inédito que the deu consistência nunca antes alcançada.

Conhecemos pouco a formação intelectual de Varnhagen, a não ser o treinamento como auto-didata, na exeperiência de longos anos, junto aos arquivos. Raros são os autores estrangeiros citados em suas cartas. Sua preocupação e maestria quanto à exegese documental parecem revelar a influência de Ranke (1795-1885), à qual poderia também inclinar-se por razões do meio familiar, sendo o pai alemão. A História Geral construída essencialmente com documentos, correspondia, sob êste aspecto, aos preceitos dò Instituto. Mas há uma nova atitude, uma nova tecitura mental no trato dos textos. A análise crítica rigorosa precede o reconhecimento da validade das fontes e sua erudição se nutre do conhecimento extenso das mesmas. Afasta o lendá- 
rio e o maravilhoso, assim como os juízos de valor alimentados pelo ufanismo. A História Geral se filia à História Filosófica, inscrita entre os objetivos do Instituto, ou seja, aquela que deve ser dominada pelo pensamento científico, pela soberania da razão. O amor à verdade mais de uma vez o levou, na sua obra, diz êle, "a combater certas crenças ou ilusões, que já nos havíamos acostumado a respeitar", os "apregoados heroismos", ante os quais devia primar "a verdade dos fatos". A verdade objetiva continha-se nos documentos, "as provas que mediante aturado estudo" conseguiu reunir. O alicerce da construção histórica está nos eventos fidedignos, reconhecida a validade do documento, mas a apreciação repousa no juízo moral. O historiador é o juiz, que sertencia imparcia!mente aos delinqüentes e premeia o mérito. Assim podemos compreender alguns característicos da obra. Ainda que seja uma História Geral, no esfôrço para abranger todos os aspectos da vida nacional, da consciência do Autor, é sobretudo uma história político-administrativa, vasada em sólida estrutura de fatos, "massa ciclópica de materiais", nas palavras de Kapistrano de Abreu. Em suma, uma História factual, um paradigma da História empírica, individualista e psicológica. Harmoniosa e equilibrada em seu desenvolvimento, assim modelada conscientemente pelo Autor. E' também uma história das elites, do qual o Autor era um expoente; digamos, um espêlho do Autor, cujos preconceitos de classe podem ser fàcilmente rastreados. Sob êste aspecto, o juízo de Capistrano é muito eloqüiente:

"Os pródromos da nossa emancipação política, os ensaios de afirmação nacional que por vêzes percorriam as fibras populares, encontram-no severo e até prevenido. Para êle - a conjuração mineira é uma "cabeçada e um conluio", a conjuração baiana de João de Deus é um cataclisma; a evolução pernambucana de 1817 uma grande calamidade, um crime em que só tomaram parte homens de inteligência estreita ou de caráter pouco elevado. Sem D. Pedro a Independência seria ilegal, ilegítima, subversiva, digna da forca ou de um fuzil. Juiz de Tiradentes e Gonzaga, êle não teria hesitado em assinar a mesma sentença que o desembargador e seus colegas".

A crítica feita por D'Avezac de que havia aplicado o plano de Martius, apresentado ao Instituto, sôbre como se devia escrever a História do Brasil, respondeu:

"a um homem que meditou sua obra é injusto dizer-lhe que achou para ela o programa feito por Martius, quando aliás o achou em todos os tratados do dia àcêrca do modo como se deve escrever a História geral de qualquer nação". 
Ligam-se à atividade estimulante do Instituto numerosos trabalhos realizados no século passado com respeito à História das províncias e municípios que projetaram na historiografia brasileira os nomes de Pereira de Alencastre, Alincourt, Fernandes Gama, Silva e Souza, Azevedo Marques, Machado de Oliveira, I. Acioli Cerqueira e Silva, Almeida Coelho, João Francisco Lisboa, Cândido Mendes de Almeida, Costa Rubim e tantos outros. Realizaram tarefa muito importante, pois devassaram os arquivos locais, leram documentos por vêzes hoje extraviados, eventualmente recolheram também, da bôca das testemunhas, a tradição oral ainda viva. A importância dêsses trabalhos foi definitiva para o alargamento do campo conhecido sôbre os fatos do passado. O característico de suas obras quanto ao método é a descrição dos acontecimentos sob critério cronológico. Pertencem à História factual, e, reconhecidas as cambiantes, à constelação de idéias de Varnłagen.

Justamente quando desaparecia o autor da História Geral do Brasil, começava a surgir nas letras históricas a figura singular de João Capistrano de Abreu (1853-1927). Não cabe neste breve comentário, estudar a evolução do pensamento do grande historiador, desde seus preparatórios em Recife, com o intuito de estudar Direito, ou da influência de positivismo, de Comte ou de Spencer, ou de suas primeiras preocupações intelectuais. Limitamo-nos a procurar compreender sua posição metodológica e conceitual, como o maior historiador de sua época.

Com a publicação em 1881 das primeiras análises e críticas do texto de Fernão Cardim, Do clima do Brasil e de algumas coisas mais notáveis que se achamı assim na terra como no mar, 'Capistrano já mostra um dos aspectos dominantes de sua personalidade intelectual, aquêle que foi o veio mais fecundo de seus trabalhos. Antes de tudo cabe salientar sua preocupação pelos documentos, que investigou incansàvelmente, com a persistência de sua longa vida. Comentou numerosas peças documentais, como as Informações do Brasil e suas capitanias em 1584, a História do Brasil de frei Vicente do Salvador, os Diálogos das Grandezas do Brasil e muitos outros. Distingüiu os textos fidedignos no confrônto das cópias examinadas, analisou-os implacàvelmente e reconstituiu a urdidura de sua construção íntima. Tal trabalho constitui uma lição invulgar de erudição e de capacidade analítica. O modêlo desta técnica encontramos em Prolegômenos à História de frei Vicente do Salvador.

Tal como em Varnhagen, a exegese documental, que ocupou muito do tempo de Capistrano, parece inspirar-se em Ranke, na escola histórica alemã . 


\footnotetext{
"A princípio minhas simpatias foram para a Alemanha e para a Alemanha continuam apesar de minhas restriçōes",
}

escrevia êle em 1917, influência que aponta em várias preocupações teóricas.

Varnhagen e Capistrano se encontram na preocupação fundamental pelo documento, no empênho quanto à autenticidade das fontes, na busca da verdade quanto aos fatos, quanto à objetividade da análise. Mas, diferentemente de Varnhagen que, tendo passado a maior parte de sua vida no exterior, tinha sua mente voltada quase que de exclusivo para as fontes primárias, Capistrano de Abreu, nunca deixando sua pátria, manifesta curiosidade incansável com referência às correntes do pensamento europeu, no campo das ciências sociais, em plena efervescência no meado do século. Em suas Cartas publicadas por José Honório Rodrigues, cita muitos autores das ciências sociais, objeto de suas letiuras, como Taine, Buckle, Comte, Ratzel, Spencer, Schmoller, Peschel, Sombart, Ranke, dezenas de outros. Lia bastante, teóricos e empíricos, em assuntos variados, sôbre a constante da criatura humana. Interessava-se pela história da China ou da Rússia, com a mesma insistência com que reclamava revistas européias ou americanas, ou textos sôbre minudências da história brasileira. De tudo, além de sua formidável erudição, ficou o sulco mais profundo na Geografia, quanto aos problemas das relações do homem com o meio. Em Caminhos antigos e povoamento do Brasil a abertura das vias e o desbravamento do sertão foram compreendidos numa vinculação estreita com as condições do meio natural; podemos considerá-la obra entre as pioneiras no campo da Geografia Humana do Brasil.

No livro de síntese, Capítulos de História Colonial, outras influências estão também presentes, e ma's difusamente. Sem muita preocupação pelas autoridades e datas, os Capítulos se articulam à base de alguns assuntos fundamentais, sem se prenderem estritamente no fio da continuidade cronológica. Na abordagem dos temas, revela-se u'a maneira nova de estudar o passado, graças ao aparelhamento que proporcionaram ao Autor suas leituras no campo das ciências humanas. O capítulo "O sertão" é o melhor da obra, pois em suas páginas estão bem aparentes os elementos que caracterizam a nova mensagem no estudo da História. A sensibilidade para com os fenômenos sociais pròpriamente ditos, enriquece a trama da história político-administrativa; há a preocupação de reconstruir alguns aspectos do quadro regular da vida dos homens, seja definindo o status das camadas sociais, seja recompondo os elementos de sua cultura ma- 
terial e os 'seus modos de viver. O empênho está sempre presente em marcar a cada passo, a influência dos fatôres da geografia física na ocupação do solo, como em notar a atividade econômico-social. Os homens se delineiam mais humanos em suas fainas do qüotidiano, sua vida se descreve agora, não apenas na estrutura dos quadros oficiais ou de funções oficiais, mas no seu terra-a-terra. Capistrano não se contenta em narrar os fatos mais importantes da atividade oficial, em descrevê-los à luz das melhores fontes, mas visa captar uma realidade que sentia mais complexa e para atingíla apela para elementos os mais simples como representativos do meio social. Assim, a cangica, comida do pobre em São Paulo, o "comer de arremesso", expressão típica do Pará que identifica a farinha de mandioca como alimento ordinário da população, são elementos que definem condições da existência, do mesmo modo que, dormir ao relento, implicava na utilização das peças do arreio dos animais para o descanso diário. O interêsse em informar quanto à data em que se introduziram em Mato Grosso galinhas e porcos (1723), tem o mesmo sentido de preocupações. O movimento das ruas do Rio de Janeiro nos é transmitido com o borborinho de seus carregadores; os meirinhos da cidade são descritos como gente, quase apartados do mister profissional, vestidos com casacos surrados e os calções curtos, a cabeleira empoada sob o chapeu grande e seboso.

Seria um pouco difícil reconhecer em Capistrano de Abreu o domínio de muitos conceitos que, ao seu tempo, as Ciências Sociais já haviam refinado. Faltou-lhe, por esta razão, muitas vêzes, uma problemática consistente, de modo a conferir a seu pensamento uma diretriz fundamental de interpretação para dar aos elementos de análise a argamassa da unidade teórica. Aflorou, sem dúvida, grandes problemas, inspirados nos postulados das outras ciências do Homem, sem conseguir desvendar-lhes a substância íntima da temática de base. Mencionamos aqui três exemplos que nos parecem elucidativos. Na vigorosa página, hoje clássica, sôbre a época do couro, nos Capítulos de História Colonial, pôs em evidência o condicionamento do homem aos recursos do meio, sem elevar-se ao conceito de gênero de vida, base da problemática em questão, conceito já rascunhado por Ratzel e plenamente definido em 1911 por Vidal de la Blache. Na sua crítica a Varnhagen, impressa em Ensaios e Estudos (1a. série) que reproduzimos há pouco, ao enumerar as repetidas mostras do preconceito dêsse historiador com referência à várias expressões do espírito de independência que partiram do povo brasileiro, Capistranò não se lembra de lhes atribuir a qualidade essencial, à do conceito. de classe 
social, assunto já objeto, na última década do século passado, de autores alemães tão de seu agrado, como Schmoller e Bücher. No quarto de seus Capítulos, procurou mostrar algumas normas que definem os característicos econômicos da colonização portuguêsa no Brasil (1o e $2^{9}$ parágrafos), sem compreendê-los na significação do sistema colonial, como postulado da doutrina mercantilista.

\footnotetext{
"Portugal não admitia que os filhos de outra nação puzessem o pé em terras suas no além-mar", por "questão de princípio",
}

escrevia Capistrano arrematando o assunto. Que prinćpioio?, arguimos. O conceito de mercantilismo como política de unidade econômica já se conhecia em Schmoller desde 1884 (Das Merkantilsystem...) e anteriormente em Cunningham (The growth of english industry and commerce, 1882) como expressão da luta pelo poder econômico para alcançar objetivos políticos.

Nosso comentário de modo algum visa diminuir o valor da obra de João Capistrano de Abreu, mas apenas precisar o seu alcance. Sua obra significa, sem dúvida alguma, um horisonte nôvo na historiografia brasileira. E' um continuador de Varnhagen, na sua formidável erudição, seu respeito às normas técnicas da velha escola histórica alemã . Sua mensagem original se deve, predominantemente, à assimilação dos conhecimentos da Geografia Humana que utilizou com maestria na interpretação do processo de ocupação e colonização do espaço brasileiro. Menos importante sua avaliação sôbre os fenômenos econômico-sociais. Reconhecemos a frequiência quanto à introdução de dados empíricos com respeito a êsses fenômenos, sobretudo em Capítulos de História Colonial, o que permitiu ao Autor alcançar certa consistência na informação quanto a êsses aspectos do passado, até então pouco considerados pelos historiadores. A utilização daqueles elementos se reusume em transcrição de textos, sem rigor de citação bibliográfica, sem perquerir continuidade de análise e sem preocupação de interpretação teórica. Mas o simples fato de haver o historiador the dado foros de material significativo para a compreensão da realidade, de haver dado dimensões novas a esta realidade, significa novas perspectivas que se descortinavam no exame do passado. O homem comum aflora aqui e ali, e o estilo ameno da narrativa, a linguagem concreta, viva do Autor, ajusta-se à sua figura .

$\mathrm{Na}$ cronologia de sua vida, João Capistrano de Abreu se coloca - entre duas concepçôes de História: a História como narrativa do em- 
pírico, dentro do juízo moral, que tem em Varnhagen; no Brasil, seu representante máximo, e a História no quadro das ciências sociais, numa dimensão nova, segundo o caminho apontado em 1900 por Henri Berr. O grande historiador cearense tem a significação de um elo entre essas duas gerações. Na história da evolução do pensamento brasileiro, não desfruta sòzinho esta hierarquia, mas a compartilha com outros grandes intelectuais de seu tempo, como Silvio Romero, Tobias Barreto, Euclides da Cunha. Expressaram a sua inquietude em compreender a realidade brasileira com o apêlo das novas correntes científicas que, ao seu tempo, se desenvolviam vigoramente no campo das ciências do Homem. 